\title{
A MÍDIA E AS DIZIBILIDADES SOBRE O SEMIÁRIDO BRASILEIRO
}

Érica Daiane da Costa Silva ${ }^{1}$

\section{Resumo:}

As diversas dizibilidades sobre o Semiárido Brasileiro apresentadas pela mídia tem sofrido variações ao longo das últimas décadas. De um lado aparece um Semiárido vitimado pelas condições climáticas que geram miséria, provocam migrações. De outro, uma nova realidade baseada no modelo desenvolvimentista apresentado sob a forma de progresso. Na contramão, a Comunicação para Convivência com o Semiárido busca mostrar outros ângulos, provocar outras compreensões, e principalmente chamar atenção para a ausência de políticas públicas apropriadas e de uma comunicação democrática.

Palavras-chaves: Semiárido; Mídia; Convivência; Comunicação

\section{Abstract:}

The various dizibilidades on the Brazilian Semiarid presented by the media has undergone changes over the past decades. On one side appears a Semiarid victimized by climatic conditions that create misery, causing migrations. In another, a new reality-based developmental model presented in the form of progress. Contrary, Communication for Coexistence with Semiarid search show other angles, cause other understandings, and especially call attention to the lack of appropriate public policies and democratic communication.

Keywords: Semiarid; media; Coexistence; Communication.

\section{Resumen:}

El modo de los medios masivos reportaren a la zona semiárida de Brasil han presentado variaciones en las ultimas décadas. De manera general, es presentada

\footnotetext{
${ }^{1}$ Comunicadora Social - Jornalista, com Especialização em Ensino da Comunicação Social e integranteda Equipe do Instituto Regional da Pequena Agropecuária Apropriada - IRPAA.
} 
una región victimizada por las condiciones climáticas de sequía que generan miseria y promueven migraciones. De otro lado, exhiben una nueva realidad, basada en el modelo desarrollista asociado a la idea de progreso. En la contravía, aparece la Comunicación para el Convivio con el Semiárido, que busca ángulos alternos para promover otras comprensiones, y principalmente chamar la atención de la sociedad para la ausencia de políticas públicas contextualizadas a la región y la necesidad de una comunicación democrática.

Palabras clave: Semiárido; Media; Comunicación.

\section{Introdução}

A crítica acerca dos estereótipos e estigmas criados, reproduzidos e reforçados sobre o Semiárido brasileiro é algo já inerente à defesa de uma Educação Contextualizada à referida região. Os currículos escolares e o livro didático são exemplos de elementos analisados considerando tal ponto de vista, o qual através de imagens e textos acaba por construir diversas inverdades que são incutidas principalmente na cabeça das crianças de outras regiões do país e mesmo do Semiárido.

Outro elemento, no entanto, que também merece uma atenção especial neste debate são os Meios de Comunicação de Massa (MCM). De início, é possível apontar os noticiários, programas de entretenimento, novelas e afins como importantes emissores de mensagens que influenciam diretamente na formação da opinião dos/das brasileiros e brasileiras. A população que diariamente acessa informações sobre o país e o mundo através da televisão, jornais, rádio e cada vez mais da internet, recebe, sem muito questionar, o que lhes é transmitido.

Esses canais muitas vezes cometem o equívoco de não diferenciarem Semiárido de Nordeste e muitas vezes de Sertão. Sob esta ótica, durante muito tempo foi crescente a visão do sertão nordestino como uma região pobre, com um povo sertanejo sofrido, que precisava migrar para outras regiões do país fugindo dos castigos da seca e da pobreza do sertão. Nos períodos da estiagem, principalmente, não havia ser humano que conseguisse se manter bem nesta região de sol 
causticante, terra infértil e chão rachado em lugares onde há algum tempo havia sido depósito de água. E assim, construía-se o imaginário popular, algo que foi amplamente reproduzido e massificado pela mídia brasileira.

\section{Comunicação e poder simbólico}

Por ser essencial à existência humana, a comunicação está presente em todo e qualquer ambiente, em todas as formas de organização social e contribui para a transformação dos significados que as pessoas atribuem às coisas, colaborando na mudança das crenças, dos valores e dos comportamentos. França (2005), diz que a comunicação está em diversos espaços do cotidiano das pessoas, a exemplo das bancas de revistas, da programação da TV, das propagandas de outdoors, nas campanhas eleitorais, chegando a ser uma presença "quase exaustiva" na sociedade atual.

Neste sentido, a comunicação, juntamente com a educação, é a responsável pela formação política, social e cultural de toda a população, especialmente na contemporaneidade. Entretanto, os meios de comunicação, sobretudo os de massa, teoricamente divulgadores da informação de qualidade, isenta e preocupada com o bem estar social, na prática, não cumprem por completo esta função.

É clara, portanto, conforme as contribuições de Porter (1958 apud Beltrão e Quirino 1986, p. 37), a herança da tradição de uma função educadora, que pode ser tomada no sentido benéfico ou não, usada para atender interesses particulares ou coletivos. Sobre a função educativa e influência direta dos MCM na vida das pessoas, o autor afirma:

Aquilo que é visto, ouvido e lido sob forma de CM [Comunicação de Massa] influencia o comportamento do indivíduo desde o momento que desperta até a hora de dormir. Afeta o modo pelo qual os negócios são operados, a corte é feita, a liberdade é definida, a causa pública é conduzida... Poucos negam que toda essa exposição influa tanto sobre o indivíduo como sobre a sociedade. Há disputas, contudo, quanto à quantidade dessa influência e sobre se essa influência é boa ou má.

Deste modo, a comunicação e a informação se estabelecem enquanto poder, ao contribuírem para a construção da realidade de cada época, ou seja, relaciona-se 
com o modelo de sociedade existente no país. Bolaño (2000) e Guareschi (2004) concordam ao se referirem à comunicação e à informação como algo estreitamente ligado ao processo de dominação ideológica.

Nesta mesma linha, ao referir-se ao poder midiático, as contribuições de Ramonet (2005) consideram que o poder faz uso da comunicação. Para esse autor, um padrão de vida é apresentado através da programação de veículos como rádio e televisão, um modelo transmitido pela imprensa, constituindo assim uma ação do sistema midiático que se configura como aparato ideológico da globalização.

A leitura da obra de Guareschi (2004) e Amaral (2000) permite compreender que, como nem sempre o exercício de poder acontece de forma explícita, no âmbito dos meios de comunicação, uma das estratégias de dominação ideológica se concretiza através da formação da opinião pública. Esta ação ocorre nas mais variadas possibilidades de comunicação oferecidas pelos meios técnicos e se caracteriza como prática inerente aos objetivos da Comunicação de Massa.

Especialmente neste novo ambiente, de uma sociedade amplamente mediada pelos meios, sobretudo tecnológicos, de comunicação e informação, as verdades, as opiniões e, consequentemente, os indivíduos são forjados, legitimando, deste modo, o poder da comunicação. Não há dúvida de que a atual realidade de conflitos de classes, onde o monopólio do capital se expressa nas mais variadas circunstâncias, traz consigo também o poder da comunicação em favor da construção e reprodução de tal realidade.

Para manter esta lógica, um dos objetivos permanente dos detentores do poder é ter o monopólio dos setores ligados à produção e difusão da informação. No Brasil, esta afirmação se confirma facilmente a partir da análise do modelo comunicacional que se instaurou e resiste até hoje. Tal como era a relação de poder na estrutura agrária existente, a realidade da comunicação foi se desenhando, com vistas a garantir a manutenção do status quo. A utilização dos meios de comunicação, desde os mais artesanais aos que chegavam no ritmo do desenvolvimento industrial no mundo, concentrava-se nas mãos das poucas famílias que constituíam a oligarquia econômica e política das formas de governo que foram sendo implantadas.

A concentração da propriedade da terra no Brasil foi determinante para a centralização do poder político. Nessa lógica de dominação, alguns autores 
denunciam o monopólio dos meios de comunicação como algo que tem contribuído para a manutenção desta realidade, apontando para a existência de "latifundiários do ar". Guareschi (2004, p. 19), escreve que "o monopólio da propriedade privada da terra, os latifúndios, se prolongam no monopólio do poder político como dominação e passam a abranger, logicamente, o monopólio dos meios de comunicação social, a serviço da dominação ideológica".

Conforme as contribuições de Thompson (1998, p. 21), o poder simbólico ou cultural tem origem na atividade de produção, transmissão e recepção dos significados. Este último tem como principal recurso os meios de informação e comunicação.

\section{Abordagens midiáticas sobre o Semiárido Brasileiro: breves reflexões}

A reprodução do estereótipo do Semiárido como uma região que se caracteriza principalmente pelo atraso e falta de perspectivas de desenvolvimento e até mesmo imprópria para ser habitada ou um lugar pobre, onde a seca destrói vidas e por isso precisa ser combatida, ainda é uma realidade. Isso se deve em grande parte aos meios de comunicação que legitimam os interesses das elites políticas, econômicas (donas dos grandes meios de comunicação do Brasil) em negar a viabilidade da região semiárida.

Como resultado de um comparativo entre a abordagem que predomina na "grande" mídia - geralmente com sedes na região sudeste do país - e as realidades do Semiárido Brasileiro, tem se a constatação de que é necessário mais conhecimento acerca da região e maior interesse em divulgar as possibilidades de convivência com o clima, a ausência de políticas permanentes e adaptadas, a diversidade cultural.

Há uma enorme carência de uma produção midiática regionalizada e comprometida com o desenvolvimento social e ambientalmente sustentável. Assim, os conteúdos produzidos e divulgados pelos MCM, especialmente pela televisão e o meio impresso, continuam a reforçar uma visão equivocada do Semiárido, negando ou omitindo as possibilidades de Convivência com o mesmo. 


\section{O "combate à seca"}

Ainda é recorrente no meio político e na mídia o uso da expressão "Combate à Seca" quando se faz referência aos efeitos e consequências deste fenômeno da natureza comum a uma região de clima semiárido. Políticas emergenciais, obras diversas, programas e projetos, caros aos cofres públicos e nem sempre eficazes, durante muito tempo foram desenvolvidos tomando por base o discurso de que a seca no Nordeste brasileiro precisava ser combatida.

A seca, no entanto, faz parte do conjunto de características do clima semiárido, assim como as temperaturas médias elevadas, a alta evapo-transpiração e as precipitações anuais irregulares e concentradas, o que faz ocorrer períodos de chuvas e de estiagens. Quanto à chuva que cai, existe a má distribuição no tempo e no espaço geográfico. Outra condição natural que favorece a existência da seca são os solos de origem cristalina, rocha dura que não favorece a acumulação de água, sendo estes $80 \%$ do total dos solos da região que compreende o Semiárido Brasileiro.

Entretanto, é possível dizer que há um potencial hídrico do Semiárido Brasileiro e que o estabelecimento de políticas públicas voltadas para esta realidade climática poderia garantir o acesso à água para todas as famílias desta região (SANTOS, SCHISTEK, OBERHOFER, 2007). Estas ações, no entanto, precisam ser estruturantes, pensada para dar conta de soluções à longo prazo, pois, conforme estudos do Centro Tecnológico da Aeronáutica (CTA), em São José dos Campos $\mathrm{SP}$, as secas são cíclicas e acontece de intensidade menor de 13 em 13 anos e com período mais prolongado de 26 em 26 anos. Porém, fatores como as mudanças climáticas, o aquecimento global do planeta terra, tudo gerado a partir da própria ação humana, pode alterar tais previsões no Semiárido do Brasil.

Diante da argumentação técnica e científica estudada ao longo dos anos, o uso da expressão e a lógica do "Combate" têm sido veementemente contestados por diversos segmentos que pautam a Convivência com o Semiárido. Apesar disto, esta visão equivocada ainda persiste. As abordagens midiáticas por sua vez contribuem para isso.

Embora se perceba a mudança de abordagem em alguns meios de comunicação, o sensacionalismo ainda é bastante presente quando se trata 
principalmente de reportar as dificuldades enfrentadas no período das estiagens por famílias sertanejas que vivem no campo. A maior parte das coberturas midiáticas aponta apenas para os efeitos da seca, sem mencionar o papel do Estado na garantia de alternativas de Convivência com o clima e com a região.

Pouco se explora o fato das secas serem fenômenos cíclicos e previsíveis e a possibilidade de preparação para enfrentá-la. Algo que também ainda não é suficientemente aproveitado é a veiculação de informações acerca da produção agrícola e animal adaptada às condições climáticas. É comum, por exemplo, matérias que mostram o impacto da seca sobre rebanhos bovinos, porém não informam que o gado não é um tipo de animal apropriado ao clima semiárido, pois são de grande porte, logo consomem grande quantidade de água, ração e, consequentemente, são mais caros.

É sabido que ainda há uma forte campanha de manutenção da famigerada "indústria da seca". A lógica do "combate" só vem a contribuir para isso e enquanto os grandes conglomerados de mídia estiverem sob a égide da elite política, econômica e muitas vezes latifundiária do país, e sem nenhuma forma de intervenção da sociedade civil que pode contrapor, certamente, essa concepção continuará a ser amplamente massificada.

\section{0 progresso que chega}

É importante dizer também que nas últimas décadas uma nova pauta tem ganhado espaço nos meios de comunicação quando o alvo é o Semiárido brasileiro, mais precisamente a parte nordestina. Também com um propósito claro, compartilhado pelos governos e empresas que financiam os grandes grupos de comunicação no Brasil, a mídia cumpre o papel de difundir um modelo de desenvolvimento baseado nos grandes projetos.

Nessa nova abordagem, o sertão ganha uma nova face, veste-se com o verde das grandes áreas irrigadas, dos grandes cultivos de cana-de-açúcar, uva, manga, soja, dentre outras monoculturas para exportação. Junto com isso, vem a promoção de empresas nacionais e multinacionais, de estatais, empresas públicas e privadas interessadas em vender um Brasil produtor, rico, em pleno desenvolvimento. Com muitos dados que dão conta dos altos investimentos, ampla produção e lucros, os 
conteúdos jornalísticos apontam uma "saída" para o Sertão, que até então era cenário de desolação.

Assim, quem não conhece o Semiárido, o Nordeste, o Sertão, a partir destes conteúdos produzidos e reforçados no imaginário da sociedade por meio da abordagem midiática, tende a construir a imagem de uma região que superou o "atraso" de outrora. O argumento da geração de emprego, os números do agronegócio referendados no crescimento do mercado internacional, o investimento em tecnologias de última geração é o que se sobressai no processo de divulgação desta nova realidade. O Rio São Francisco, as Caatingas, as serras, os solos férteis, as culturas típicas do povo sertanejo, tornaram-se alvo de programas e ações grandiosas que se dizem baseadas em um desenvolvimento sustentável.

No entanto, a sustentabilidade é um elemento pouco possível neste processo e a mídia age de forma conivente, sem questionar a possibilidade de ser sustentável uma forma de desenvolvimento que acirra cada vez mais as desigualdades sociais, que não preserva os recursos naturais, que produz alimento para exportação enquanto mais de $60 \%$ da população do Semiárido Brasileiro vive em situação de extrema pobreza, segundo o IBGE (Instituto Brasileiro de Geografia e Estatística). O Brasil assiste, ouve e lê uma mídia que pouco evidencia os interesses políticos eleitoreiros por trás de obras faraônicas como a Transposição do Rio São Francisco, por exemplo, que se arrasta há mais de cinco anos, com um orçamento que pulou de 4,6 bilhões para 8,2 bilhões (aumento de quase $80 \%$ ) e as obras - inacabadas - já em estado de deterioração.

\section{Só o campo é Semiárido}

Está arraigado no imaginário das pessoas, inclusive dos segmentos que discutem a viabilidade do Semiárido, uma forte associação entre Semiárido e campo. Os diversos elementos que compõem o paradigma da Convivência com o Semiárido são pensados em sua maioria para o meio rural, no entanto, é imprescindível repensar esta lógica, uma vez que as áreas urbanas são parte deste contexto. Embora no que tange ao acesso a alguns direitos e serviços o meio urbano possa apresentar vantagens com relação ao campo, o clima da região é válido para todas as áreas geográficas que compreende o Semiárido Brasileiro. 
Semiárido é o clima, mas também uma denominação para uma região do país, cuja permanência nela precisa ser pensada a partir de aspectos sociais, econômicos, políticos, coerentes com a diversidade climática, questão central do debate. Nisto, sejam as áreas urbanas ou rurais precisam contar com ações e medidas apropriadas.

A mídia, no entanto, pouco apresenta esta visão. É comum os noticiários fazerem referência ao Semiárido como sendo apenas as áreas rurais, onde em sua maioria predomina a escassez de d'água, ou, como já foi mencionado, onde há o crescimento do agronegócio, sob a ótica do campo como gerador de riquezas. Faz falta, neste sentido, uma problematização por parte dos meios de comunicação, os quais muito poderiam contribuir com a desconstrução desta visão equivocada que acaba por isolar, em certa medida, o meio urbano das discussões acerca da Convivência com o Semiárido.

Este é um problema, paradoxalmente, atual. Sua existência persiste apesar da difusão das inovações tecnológicas e das informações produzidas nas capitais ou grandes centros ser crescente no dia a dia do campo. De acordo com Fadul (1976), a influência dos MCM nas regiões menos desenvolvidas provoca um processo de decadência da cultura regional e isso, por sua vez, favoreceria essa condição do campo aparecer como sinônimo de Semiárido, onde as condições de vida seriam inferiores, separando assim as cidades deste contexto.

\section{Comunicação para Convivência com o Semiárido: outras dizibilidades}

No intuito de desconstruir os estereótipos e promover uma comunicação diferenciada, que considere a viabilidade da Convivência com o Semiárido em sua essência, fazendo valer o direito à comunicação dentre os elementos chaves para consolidação deste paradigma, diversas iniciativas aos poucos foram se materializando, especialmente no campo da sociedade civil organizada.

O entendimento de que a imagem caricata do Semiárido propagado pela mídia faz parte de um conjunto de interesses favoráveis aos grandes conglomerados de comunicação do Brasil foi essencial para o despertar das possibilidades de uma comunicação contra hegemônica. Anunciar realidades e contextos que apresentam outro Semiárido, a necessidade da ação política e a presença de um imenso jogo de 
interesses no campo empresarial da comunicação brasileira tornou-se a orientação base para propor uma nova pauta para a sociedade quando se falasse em Semiárido Brasileiro.

Com esse propósito, as pastorais sociais, ONG's (Organizações Não Governamentais), cooperativas e associações, sindicatos e hoje até Universidades se apropriaram de estratégias de comunicação diversas, a exemplo da formação de redes de comunicadores/as populares, crescimento das assessorias de comunicação no âmbito do terceiro setor, criação de mídias comunitárias, uso do rádio, da internet. Instrumentos e formas de comunicar são pensados para atingir públicos diversos, do campo e da cidade, da academia e dos movimentos sociais, do âmbito político, empresarial até o conjunto da população que experiência alternativas de Convivência com a região. Experiências, resultados, além de um imenso leque de informações ancoradas no conhecimento aprofundado sobre esta região, são amplamente difundidos.

Cabe aos adeptos a esta outra comunicação, estimular a produção independente de mídias que atendam a demanda local, a exemplo de boletins, uso de rádios comunitárias e alto falantes, vídeos, blogs. A indissociável relação entre a educação e a comunicação também é vista como caminho essencial na formação de sujeitos conscientes da necessidade de promover realidades que levem em conta as especificidades de cada região do país.

Nesta nova empreitada, os conteúdos sugeridos como pautas centrais devem então reportar-se aos aspectos da viabilidade da Convivência com o Semiárido, com a preocupação de sempre abordar conceitos e práticas relacionados a temáticas como: as características climáticas, a produção agropecuária adaptada, a necessidade da preservação ambiental (a exemplo do cuidado com os rios, com as Caatingas, a flora e a fauna, com o lixo, o saneamento básico, etc), manutenção das famílias em suas terras, segurança alimentar, valorização da cultura regional, educação contextualizada, implementação de técnicas e tecnologias apropriadas às condições de clima e solo, organização e comercialização da produção, cooperativismo.

Neste sentido, tem sido crescente a produção de materiais por parte de diversas organizações sociais, as quais apresentam um olhar sobre o Semiárido a partir da lógica da Convivência e apontam caminhos, estes baseados em 
experiências concretas que geraram resultados positivos. Existe já uma vasta produção paradidática, além do trabalho de assessoria de imprensa e a manutenção de mídias institucionais que lançam para a sociedade as possibilidades de viver com dignidade no Semiárido. Cartilhas, livros, vídeos, revistas, boletins informativos, programas de rádios, sites, perfis em redes sociais e diversos outros instrumentos mostram como é pensada e posta em prática nos diversos estados do Semiárido Brasileiro as ações de Convivência com a região.

\section{CONSIDERAÇÕES FINAIS}

Não foi por acaso que esta imagem do Nordeste (e do Semiárido) foi construída e reforçada no imaginário do país, sobretudo na visão das regiões mais "ricas", grandes detentoras do capital advindo da industrialização, principalmente.

A indústria da seca permitiu que inúmeras famílias do Nordeste se perpetuassem na política, aumentando cada vez mais o poder econômico de diversas gerações de famílias ricas (latifundiárias). Essas famílias, por sua vez, detêm até hoje também o controle de meios de comunicação de grande alcance, a exemplo de grupos empresariais de comunicação na Bahia, em Alagoas, no Ceará, em Pernambuco, etc. Estas, portanto, ditam formas de desenvolvimento para a região sob a máscara de uma "opinião pública".

A partir de novos paradigmas, numa tentativa "bem sucedida" de desconstruir a imagem negativa da região e "aproveitar" seu potencial para gerar riquezas, as atenções dos governos e empresas voltam-se para a consolidação de uma política desenvolvimentista, apresentando agora para o resto do país e para o mundo a região como sinônimo de potencialidades a serem exploradas em prol do desenvolvimento econômico. Desenvolvimento, porém, que chega para uma minoria.

$\mathrm{Na}$ contramão disso, as iniciativas de subversão desta lógica. A inquietação diante de um poder estabelecido, o "quarto poder", faz reluzir outras possibilidades de comunicar realidades que distam do que aparece sob a ótica dos donos da mídia. Há um caminho muito longo sendo trilhado, onde se espera chegar a uma Política Nacional de Convivência com o Semiárido merecida pelo povo desta região. A comunicação popular, a comunicação como direito humano - que deve ser tão 
assegurado quantos outros direitos fundamentais (água, terra, saúde, alimentação, educação, entre outros) - precisa ser reconhecidos nesta Política almejada para esta importante região do Brasil.

É importante considerar que já houve avanços no que diz respeito à abordagem da mídia convencional, totalmente monopolizada, parte de uma estrutura que se assemelha a realidade do latifúndio no Brasil. Especialmente em âmbito regional, os principais meios de comunicação (maiores em alcance e consequentemente em audiência) já produzem abordagens que se aproximam dos anseios desta comunicação que se faz do lado de cá. Contudo, espera-se mais. Faz-se muito necessária uma mídia séria, comprometida, responsável, com uma programação que contemple a diversidade, as dificuldades, mas que contribua com a resolução dos anseios populares, que seja qualificada, pois sabe-se que seu poder de alienar é tão grande quanto seu poder de libertar, de persuadir e fomentar nas pessoas uma visão crítica-ativa, uma percepção de que o Semiárido é viável e portanto assim deve ser tratado. 


\section{REFERÊNCIAS}

AMARAL, Roberto. Controle das eleições e informação: o papel dos meios de comunicação de massa. In: Revista Comunicação e Política. 2. ed. Rio de Janeiro: Cebela, 2000. p. 146-149.

BELTRÃO, Luiz; QUIRINO, Newton de Oliveira. Subsídios para uma teoria da comunicação de massa. São Paulo: Summus, 1986.

BOLAÑO, César. Indústria cultural: informação e capitalismo. São Paulo: Hucitec/Polis, 2000.

FADUL, Anamaria. Decadência da cultura regional: a influência do rádio e da Tv. In: MELO, José

Marques de (coord.). Comunicação/incomunicação no Brasil. São Paulo: Loyola, 1976. p. 49-54.

FRANÇA, V. V. O objeto da comunicação/a comunicação como objeto. In: HOHLFELDT, A.; MARTINO, L. C.; FRANÇA, V. V. (Org.). Teorias da comunicação: conceitos, escolas e tendências. 5. ed. Petrópolis: Vozes, 2005.

GUARESCHI, Pedrinho A. (Coord.). Comunicação e controle social. 6. ed. Petrópolis: Vozes, 2004.

RAMONET, Ignacio. O poder midiático. In: MORAES, Dênis de (Org.). Por uma outra comunicação. 3. ed. Rio de Janeiro: Record, 2005. p. 243-252.

SANTOS, C. F.; SCHISTEK, H.; OBERHOFER, M. Viver no Semiárido é aprender a conviver: conhecendo o Semi-árido em busca da convivência. Juazeiro - BA. Novembro, 2007.

SILVA, Érica Daiane da Costa. A Comunicação e as lutas pela água no Vale do Salitre - Juazeiro-BA. Monografia do curso de graduação em Comunicação Social - Jornalismo em Multimeios. Universidade do Estado da Bahia - UNEB. Juazeiro BA, 2010.

THOMPSON, John B. A mídia e a modernidade: uma teoria social da mídia. Petrópolis: Vozes, 1998.

- Plano de Comunicação do Instituto Regional da Pequena Agropecuária Apropriada - IRPAA. Ano: 2012.

- Cartilha dos 20 Anos do Instituto Regional da Pequena Agropecuária Apropriada IRPAA. Ano: 2011 